\title{
Comparative Pulmonary Responses Caused by Exposure to Standard Cobalt and Ultrafine Cobalt
}

\author{
Qunwei Zhang ${ }^{1 *}$, Yukinori Kusaka ${ }^{1}$ and Kenneth Donaldson ${ }^{2}$ \\ 'Department of Environmental Health, School of Medicine, Fukui Medical University, \\ Department of Biological Sciences, Napier University, Edinburgh, UK
}

\begin{abstract}
Comparative Pulmonary Responses Caused by Exposure to Standard Cobalt and Ultrafine Cobalt: Qunwei ZHANG, et al. Department of Environmental Health, School of Medicine, Fukui Medical University-The aim of this study was to compare the pulmonary toxicity after exposure to standard cobalt (Std-Co) and ultrafine cobalt (Uf-Co). Rats were intratracheally instilled with $1 \mathrm{mg}$ of Std-Co and Uf-Co, and wet lung weight and bronchoalveolar lavage fluid (BALF) profiles were analysed 1, 3, 7, 15 and $30 \mathrm{~d}$ later. The effects of Std-Co and Uf-Co on indices that can be presumed to reflect epithelial injury and permeability (lactate dehydrogenase (LDH) and total protein (TP)), and release of proinflammatory cytokine (tumor necrosis factor-alpha (TNF-alpha)) were increased throughout the $30 \mathrm{~d}$ post-exposure period. The results showed that the effects of Std-Co and Uf-Co on these indices were significantly higher than those of control. The results also showed that the effects of Uf-Co on indices were significantly higher than those of Std-Co from 1 to $15 \mathrm{~d}$ after instillation. Moreover, the number of neutrophils and LDH activity in BALF in rats after exposure to Uf-Co were significantly greater than those of Std-Co-exposed rats up to $30 \mathrm{~d}$ after instillation. Our findings suggest that Uf-Co has a much more toxic effect on the lungs than Std-Co, but the mechanism remains to be elucidated. (J Occup Health 2000; 42: 179-184)
\end{abstract}

Key words: Ultrafine cobalt, Standard cobalt, Bronchoalveolar lavage, Lung toxicity

Cobalt is a metal that is used in many different alloys. Inhalation exposure to cobalt causes bronchial

Received Dec 15, 1999; Accepted March 25, 2000

Correspondence to: Y. Kusaka. Department of Environmental Health, School of Medicine. Fukui Medical University, MatsuokaCho. Fukui $910-119.3$, Japan

"Present address: Nelson Instinte of Entronmental Medicine, New York University Medical Centre, 550 First Avenuc. NY 100/6, USA obstruction, bronchial asthma, and interstitial pneumonitis ${ }^{1-6)}$. Cobalt is also one of the constituents of hard metals, and it is widely used in industry". Occupational exposure to cobalt and its compounds has been shown to cause lung inflammation. fibrosis, emphysema, and alveolar proteinosis ${ }^{7.8}$. Inhalation of Uf-Co also induced macrophages damage. intracellular edema of the type I alveolar epithelium, interstitial edema and proliferation of type II alveolar epithelium ${ }^{\text {"). }}$.

The toxicity of particles in the lungs is not only related to the extent of exposure but also to the particle type. For example, ultrafine titanium dioxide $\left(\mathrm{Uf}-\mathrm{TiO}_{2}\right)$ with a diameter of $20 \mathrm{~nm}$ can induce a pulmonary inflammatory reaction of a greater magnitude than $250 \mathrm{~nm} \mathrm{TiO}$ at the same mass ${ }^{1 \mid-1+1)}$. Ultrafine nickel and Uf-TiO, had also more toxicity than standard nickel and standard titanium dioxide, respectively ${ }^{12-16 !}$.

Ultrafine cobalt (Uf-Co) with a mean diameter of 20 $\mathrm{nm}$ is a new category of ultrafine particles, made by a process of vapour deposition. The characteristics of UfCo were described in detail previously $y^{4,17}$. Our previously results showed that Uf-Co can cause sustained and substantial pulmonary inflammation ${ }^{17,181}$. To date, however, there is no report on comparative pulmonary toxicity after instillation of Std-Co and Uf-Co. Our previous results also suggested that tumor necrosis factor (TNF-alpha) may play an important role in the pathogenic effects of Uf-Co ${ }^{1 \times 3}$. And TNF-alpha is a proinflammatory cytokine produced by macrophages or monocytic phagocytes in response to various stimuli, and the production of TNF-alpha in BALF can reflect the degree of inflammation in lungs ${ }^{(9)}$. Therefore, the aim of present study was to compare the toxicity of Std-Co and Uf-Co by using the bronchoalveolar lavage (BAL) technique to study the cytological and biochemical changes in the bronchoalveolar lavage fluid (BALF). 


\section{Materials and Methods}

\section{Experimental animal}

Wistar male rats (specific pathogen-free), weighing $180-200 \mathrm{~g}$ and at 7-8 wk of age were supplied by Clear Japan, INC (JCL). The rats were housed in the animal centre of Fukui Medical University, Japan. They were fed conventional laboratory diet and had free access to food and tap water.

\section{Materials examined}

1. Uf-Co powder with an average diameter of $20 \mathrm{~nm}$ on was purchased as ultrafine powder from INABTA and Co., Ltd. Vacuum Metallurgical Co., Ltd., Japan (Lot No. 2237). Uf-Co with a size of $<30 \mathrm{~nm}$ constitute more than $95.0 \%$. The size distribution of Uf-Co was detailed previously ${ }^{17 !}$.

2. Cobalt powder with an average diameter of $5 \mu \mathrm{m}$ (Std-Co) was purchased as cobalt powder from Cica Reagent, Kanto Chemical Co., Japan (Cat. No. 07385-32).

The powders were suspended in physiological saline to a concentration of $1 \mathrm{mg} / \mathrm{m} l$. The suspensions were ultrasonicated for about $30 \mathrm{~min}$ and then sterilised at 0.5 $\mathrm{kgf} / \mathrm{cm}^{2}$ and $120^{\circ} \mathrm{C}$ for $15 \mathrm{~min}$.

\section{Treatment}

The rats were randomly divided into fifteen groups of 5 to 6 rats. Each experimental rat was injected intratracheally with $1 \mathrm{mg}$ of Std-Co or Uf-Co in suspensions in $1 \mathrm{~m} /$ of physiological saline. Hereafter, rats injected with physiological saline alone were called the control group. Rats in each group were killed at 1,3, 7,15 and $30 \mathrm{~d}$ after injection.

\section{$B A L F$}

The rats were killed by an overdose injection of phenobarbital solution $(50 \mathrm{mg} / \mathrm{m} l)$ into the abdominal cavity, and the lungs and trachea were removed en bloc. The wet lung weight was measured after removing the heart, mediastinal lymphnodes and adipose tissue. The lung: the body (lung index weight ratio) was calculated. BAL was accomplished with $4 \times 10 \mathrm{~m} l$ saline warmed at $37^{\circ} \mathrm{C}$ and massage. The recovery of bronchoalveolar lavage fluid (BALF) for each rat was measured, and the $B A L F$ recovery rate was calculated. The BALF was centrifuged at $1,500-\mathrm{rpm}(27.67 \mathrm{~g})$ for $10 \mathrm{~min}$, and the first tubes were used to measure the activity of the LDH and total concentration of protein and TNF-alpha. The numbers of total cells, macrophages, neutrophils and lymphocytes were evaluated for BALF pooled from each rat.

Biochemical and cytological evaluation of BALF and biochemical evaluation in supernatant

The LDH activity in the first tube of BALF was measured with an LDH C II-test kit (WAKO Pure Chemical
Industries Ltd, Japan) by the lactate matrix method ${ }^{20)}$. The concentration of total protein in BALF was assessed by the Lowry method ${ }^{21)}$. TNF-alpha was quantified with an enzyme-linked immunosorbent assay (ELISA) kit (Biosource International). The assay utilised a standard, 96-well quantitative immunometric "sandwich" enzyme technique according to the manufacturer's recommendation protocol. Cells were obtained by centrifugation from all the BALF, and counted in a hemacytometer by the conventional method, and cell differentiation was done by the Wright-Giemsa method.

\section{Statistical analysis}

Results were expressed as the mean and standard error. The differences among groups were tested by one-way analysis of variance (ANOVA), followed by Bonferroni multiple comparison. If a $P$ value was less than 0.05 , the difference was considered significant. All statistics were obtained with SPSS 6.1.

\section{Results}

1. Recovery of BALF

The BALF recovery rate was more than $80 \%$, which did not differ significantly among the experimental and control groups. Data are not shown.

2. Wet lung weight

The absolute (data not shown) and relative wet lung weights of rats instilled with $1 \mathrm{mg}$ Uf-Co were significantly higher than those of the controls at $1,3,7$, 15 and 30 d after injection; the Std-Co groups had heavier lungs than the controls except at $30 \mathrm{~d}$ after injection (Fig. 1).

3. Cellular and biochemical constituents in BALF

Figure 2 to Fig. 6 showed the cellular and biochemical constituents in BALF at 1, 3, 7, 15 and $30 \mathrm{~d}$ after instillation. Std-Co and Uf-Co instillation caused an increase in total cells, and neutrophils in BALF. Instillation Std-Co and Uf-Co caused a strong increase in the total numbers of cells, neutrophils, LDH activity, total protein and TNF-alpha in BALF at 1 day after instillation, but, these indices were decreasing within the experimental period, but at $30 \mathrm{~d}$ after the injection of Std-Co or Uf-Co, the total numbers of cells and neutrophils in BALF were still significantly higher than those in the control groups. The increases in total cells, and neutrophils caused by Uf-Co were marked, and at all time points were significantly greater than those of StdCo (Figs. 2 and 3). The results also showed that Std-Co and Uf-Co increased LDH activity, total protein, and TNF-alpha in BALF compared with those of the control (Fig. 4 to Fig. 6). The LDH activity and total protein in BALF also decreased during the experimental period, and the $\mathrm{LDH}$ activity (except at $30 \mathrm{~d}$ ), total protein and TNFalpha in BALF were more significantly increased in the Uf-Co group than in the Std-Co groups. 


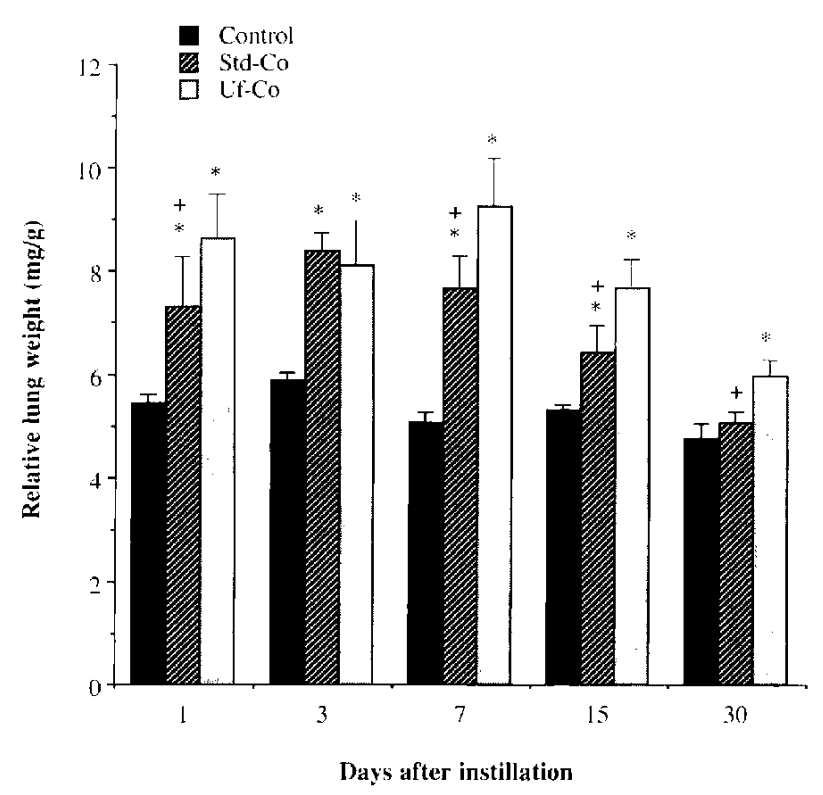

Fig. 1. Lung: hody weight ratio up to $30 \mathrm{~d}$ after instillation of Std-Co and Uf-Co. Values are the mean \pm SE for 4 to 6 rats. * indicates significantly different from the control group. $\mathrm{P}<0.05 .+$ indicates significantly different from the Uf-Ni group, $\mathrm{P}<0.05$. Shown by ANOVA with Bonferroni comparison test.

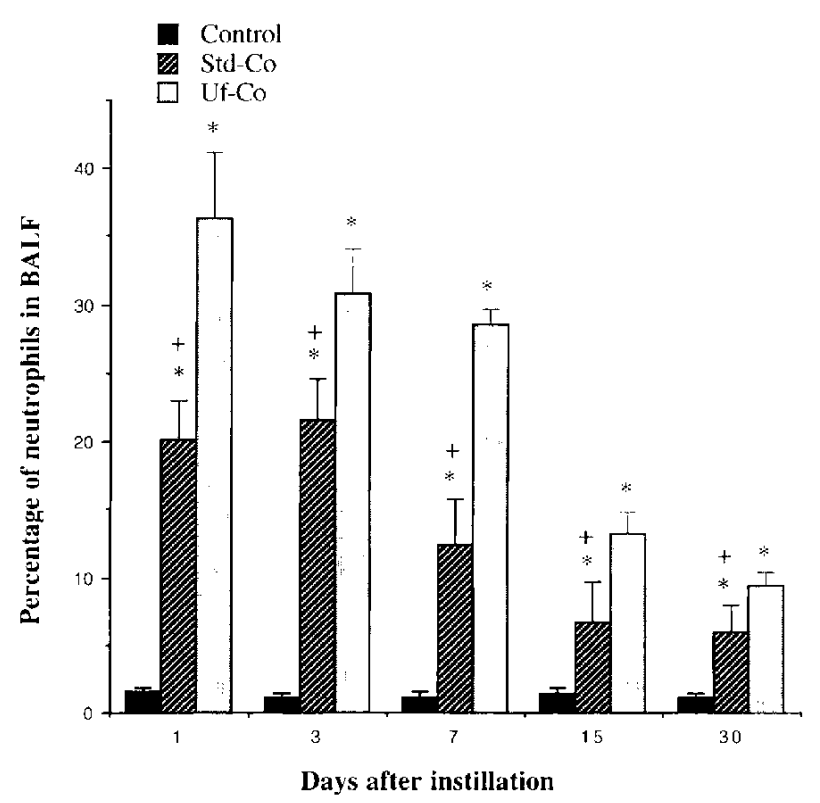

Fig. 3. Percentage of neutrophils in BALF from rats up to $30 \mathrm{~d}$ after instillation of Std-Co and Uf-Co. Values are the mean \pm SE for four to six rats. Significant differences indicated as in Fig. 1.

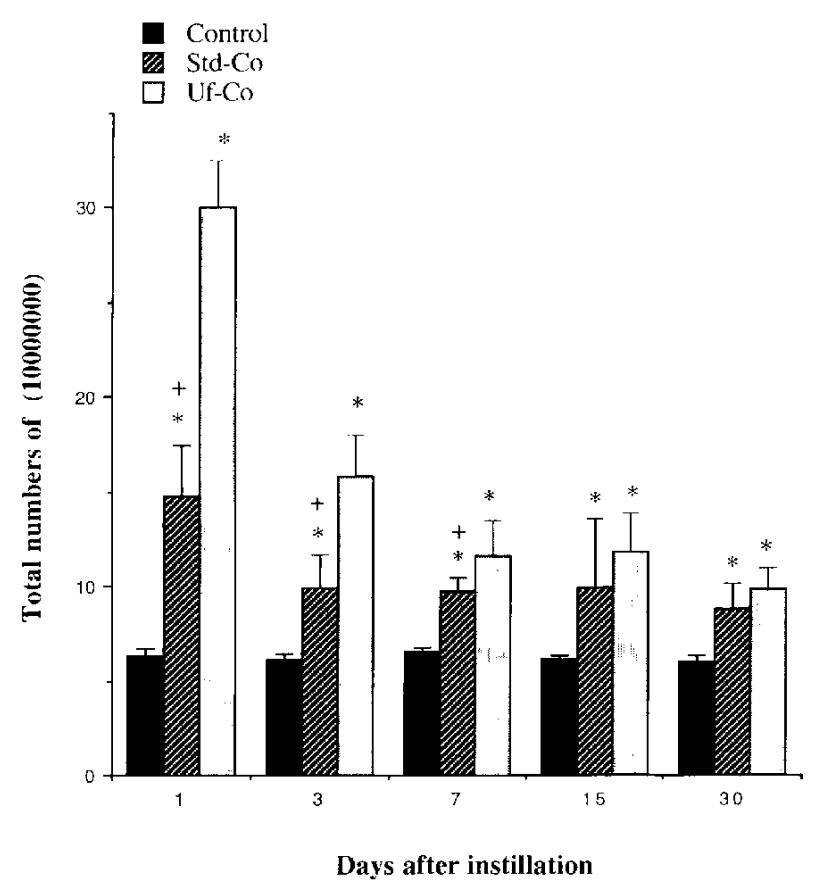

Fig. 2. Numbers of total cells in BALF from rats up to $30 \mathrm{~d}$ after instillation of Std-Co and Uf-Co. Values are the mean \pm SE for four to six rats. Significant differences indicated as in Fig. 1.

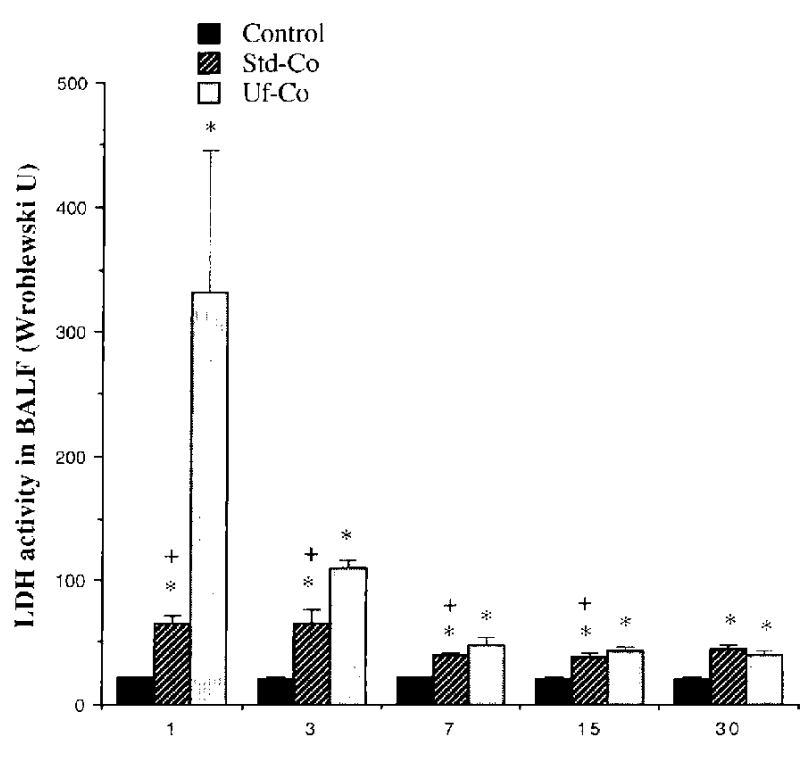

Days after instillation

Fig. 4. LDH activity in BALF from rats up to $30 \mathrm{~d}$ after instillation of Std-Co and Lf-Co. Values are the mean \pm SF for four to six rats. Significant differences indicated as in Fig. 1 . 


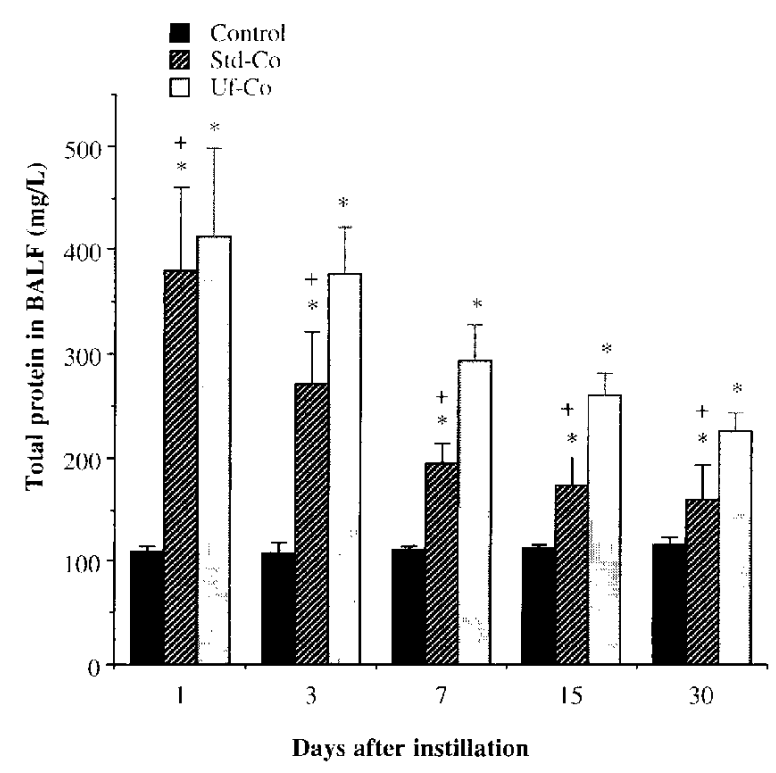

Fig. 5. Total protein in BAL.F from rats up to $30 \mathrm{~d}$ after instillation of Std-Co and Uf-Co. Values are the mean $\pm \mathrm{SE}$ for four to six rats. Significant differences indicated as in Fig. 1.

\section{Discussion}

We compared the BALF inflammatory profiles after instillation of Std-Co and Uf-Co. This technique has been used to assess the induction of lung injury by mineral dusts and metallic compounds ${ }^{22-25)}$. We have presented results clearly demonstrating that $\mathrm{Uf}-\mathrm{Co}$ is much more toxic to the lower respiratory tract than Std-Co when they are given in the same mass dose $(1 \mathrm{mg})$.

Instillation of $1 \mathrm{mg}$ Uf-Co induced pulmonary inflammation, as shown by increased lung weight sustained macrophages and neutrophil influxes, and severe injury as measured by LDH and protein in BALF. These effects of Uf-Co greatly exceeded those elicited by Std-Co. The BALF profiles suggested that this UfCo instillation may cause a sequence of events commencing with acute damage to the epithelia, resulting in $\mathrm{LDH}$ release and protein accumulation resulting from increased epithelium permeability. This may allow interstitial access of particles, leading to acute interstitial and alveolar inflammation, which are persistent bccause of the failure to clear the unsaturated particles ${ }^{12.13 .3}$.

It is generally accepted that macrophages play a key role in starting the cascade of adverse reactions to toxic particles $^{26.27}$. Neutrophils normally perform an important defensive role against microbial infection ${ }^{191}$, but when macrophages increase in number and become activated in response to particle deposition, they can release chemotactic factors that attract polymorphonuclear leukocytes and monocytes. These activated macrophages

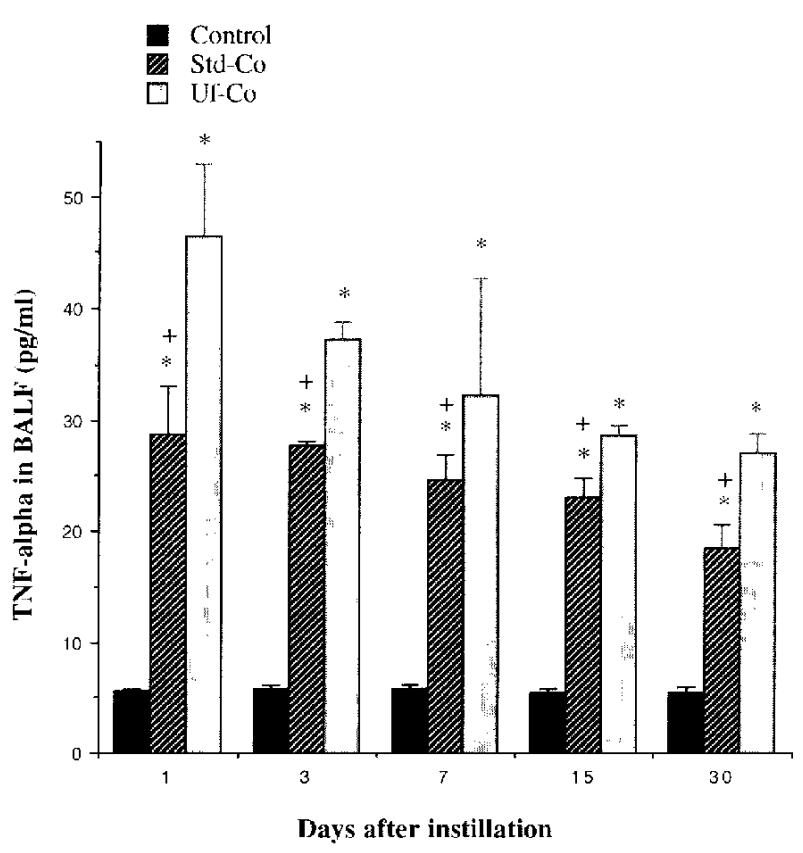

Fig. 6. TNF-alpha in BALF from rats up $1030 \mathrm{~d}$ after instillation of Std-Co and Uf-Co. Values are the mean $\pm \mathrm{SE}$ for four to six rats. Significant differences indicated as in Fig. 1 .

and neutrophils can release a variety of cytokines, toxic oxygen metabolites and proteinase that can damage the lung parenchyma ${ }^{28 !}$ and also stimulate fibroblast proliferation $^{24)}$.

TNF-alpha is a proinflammatory cytokine produced by macrophages or monocytes in response to various stimuli. Neutrophils are activated by TNF-alpha to a state where they are more likely to promote inflammation and cause injury to epithelial cells. Our results showed that instillation of Std-Co and Uf-Co caused a TNF-alpha increase in BALF that was greater with Uf-Co and that was persistent. And TNF- alpha in the Uf-Co group was significantly higher than that of Std-Co at all time points. Interestingly, an increase in TNF-alpha in BALF was accompanied by an increase in the total numbers of cells and neutrophils in BALF. It is suggested that TNF-alpha released from pulmonary leukocytes probably plays a role in the high toxicity of Uf-Co ${ }^{18 !}$.

In the case of ultrafine particles, the massive number of particles may stimulate macrophages to release these mediators in exaggerated amounts. Furthermore, the total numbers of ultrafine particles may overwhelm the capacity of the macrophages to phagocytoze and allow interaction of particles with epithelial cells leading to epithelia injury. Instillation with Uf-Co caused mild pulmonary damage, which was reflected by increased LDH activity and total protein in BALF. Uf-Co caused scvere pulmonary damage at an early stage, but this effect 
decreased during the experiment. and was reflected by the $\mathrm{LDH}$ and total protein in BALF at 30 days after instillation. Nevertheless. our previous study showed that ultraline nickel caused epithelial injury from a relatively low exposure, sufficient enough to cause death of the rats due to acute pulmonary edema ${ }^{(5)}$. Although nickel and cobalt belong to the same elemental group, ultrafine nickel was more highly and persistently toxic to lung than Uf-Co ${ }^{17}$.

This study did not elucidate the mechanism why UfCo is able to cause higher pulmonary toxicity than StdCo, but the difference between Uf-Co and Std-Co in particle diameter are the most striking characteristic, and Uf-Co has a much greater surface area than Std-Co. Particle size appears to be very important in terms of inducing lung disease after deposition in the lungs $s^{\mid 0-12.25\}}$. Furthermore, our previous studies also found that some ultrafine particles have free radical activity ${ }^{171}$, and exposure to Uf-Co can stimulate pulmonary lcukocytes to release TNF-alpha, which may underline the effects reported here.

In conclusion, our study confirmed that Uf-Co is much more toxic to the lungs than Std-Co. The data obtained from this study have potential benefit for understanding the special toxicity of Uf-Co. Since the present occupational exposure limit is based on mass only and does not take particle size into account, these findings have important implications for hygiene regulations.

Acknowledgments: This work was supported by a Grant for Scientific Research from the Ministry of Education, Science and Culture, Japan (No. 07670399).

\section{References}

1) Coates EO, Watson JHL. Diffuse interstitial lung disease in tungsten carbide worker. Ann Intern Med 1971: 75: 709-716.

2) Kitamura M, Kitamura H. Tozawa T, Kimura Y. Cemented tungsten carbide pneumoconiosis. Acta Pathol Jpn 1978: 28: 921-935.

3) Hartung M, Schaller KH, Brand E. On the question of the pathogenic important of cobalt for hard metal fibrosis of lung. Int Arch Occup Environ Health 1982; 50: $53-57$.

4) Camner P, Boman A, Johansson A, Lundborg M, Wahlberg JE. Inhalation of cobalt by sensitised guinca pigs: effects on the lungs. Bri J Ind Med 1993; 50: $753-757$.

5) Kerfoot EJ, Fredick WG, Domeier E. Cobalt metal inhalation on miniature swine. Am Ind Hyg Assoc J 1975: 36: 17-25.

6) Wehner AP, Busch RH, Olson RJ, Craig DK, Chronic inhalation of cobalt oxide and cigarette smoke by hamsters. Am Ind Hyg Assoc J 1977; 38:338-346.

7) Hartung M, Schaller KH, Brand E. On the question of the pathogenic important of cobalt for hard metal fibrosis of the lung. Int Arch Occup Environ Health
$1982 ; 50: 53-57$

8) Moulin JJ, Wild P, Mur JM, Fournier-Betz M. MercierGallay M. A mortality study of cobalt production workers: an extension of the follow-up. Am J Ind Mcd. $1993 ; 23: 281-288$.

9) Kyono H, Kusaka Y, Homma K, Kubota H, EndoIchikawa $Y$. Reversible lung lesions in rats due to shortterm exposure to ultrafine cobalt particles. Ind Health 1992; 30: 103-118.

10) Ferin J, Oberdöster G, Penney DP, Soderholm SC, Piper HC. Increased pulmonary toxicity of ultrafine particles? I. Particle clearance, translocation, morphology. J Aerosol Sci 1990: 21: 381-384.

11) Ferin J, Oberdöster G, Soderholm SC. Gelein R. Pulmonary lissue access of ultrafine particles. J Aerosol Sci 1991: 4: 57-68.

12) Oberdöster G, Ferin J, Finkelstein G, Wade P, Corson N. Increased toxicity of ultrafine particles? II. Lung lavage studies. J Aerosol Sci 1991; 21: 384-387.

13) Oberdöster G, Ferin J, Lehnert BE. Correlation between particle size, in vivo particle persistence, and lung injury. Environ Health Persp 1994; 102 (Suppl 3): 173179.

14) Takenaka S, Dornhofer-Takenaka H, Muble H. Alveolar distribution of fly ash and titanium dioxide after longterm inhalation by Wistar rats. J Aerosol Sci 1986; 17: $361-364$.

15) Zhang Q, Kusaka Y. Sato K, Mo Y, Fukuda M. Donaldson $K$. Toxicity of ultrafine nickel particles in lungs after intratracheal instillation. J Occup Health 1998; 40: 171-176.

16) Zhang Q, Kusaka Y, Sato K, Donaldson K. Dilferences in the inflammogenicity of standard and ultafine nickel: the role of nitric oxide. In: Chiyotnni K. Hosoda Y, Aizawa $Y$, eds. Advances in the prevention of Occupational Respiratory Diseases. Amsterdam: Elsevier Sciences, 1998: 866-872.

17) Zhang Q, Kusaka Y, Sato K, Nakakuki K, Kohyama $N$, Donaldson K. Differences in the extent of inflammation caused by intratracheal exposure to 3 ultrafine metals: role of free radicals. J Toxicol Environ Health 1998; 58: 423-438.

18) Zhang Q, Kusaka Y, Sato K, Wang D, Donaldson K. Tumore necrosis factor-alpha relcase from rat pulmonary leukocytes exposed to ultrafine: in vivo and in vitro studies. Environ Health and Perevent Med 1999: 4: 87-91.

19) Kelly J. Cytokines of the lung. Am Rev Respir Dis 1990; 141: 765-788.

20) Babson AL, Phillips GE. A rapid calorimetric assay for serum lactic dehydrogenase. Clin Chem Acta 1965; 12: $210-215$.

21) Lowry OH, Rosebrough NJ, Farr AL, Randall RJ. Protein measurement with the folin phenol reagent. J Bio Chem 1951; 193: 265-275.

22) Zhang Q, Kusaka Y, Zhang QF, He L, Zhang Z, Sato $K$. Dynamic changes of constituents in bronchoalveolar lavage fluid in experimental silicotic rats. Ind Health 1996: 34: 279-388.

23) Henderson RF. Use of bronchoalveolar lavage to detect 
lung damage. Environ Health Persp 1984; 56: 115 129.

24) Lindenschmidt RC, Driscoll KE, Perkins MA, Higgins JM, Maurer JK, Belfiore KA. The comparison of a fibrogenic and two non-fibrogenic dusts by bronchoalveolar lavage. Toxicol Appl Pharmacol 1990; 102: 268-281.

25) Donaldson K, Bolton RE, Jones A, et al. Kinetics of the bronchoalveolar leucocyte response in rats during exposure to equal airborne mass concentration of quartz, chysotile asbestos, or titanium dioxide. Thorax 1988; 43: 525-533.

26) Donaldson K, Brown GM, Brown DM, Slight J, Li $\mathrm{XY}$. Epithelial and extracellular matrix injury in quartz- inflamed lung: role of the alveolar macrophage. Environ Health Pers 1992: 97: 221-224.

27) Zhang Q, Kusaka Y, Donaldson K. Comparative injurious and proinflammatory effects of three ultrafine metals in macrophages from young and old rats. Inhal Toxicol 2000 (in press).

28) Kamp DV, Graceffa P, Pryor WA, Weitzman SA. The role of free radicals in asbestos-induced diseases. Free Rad Bio Med 1992; 12: 293-315.

29) Martin TR, Rang G, Merritt TL, Henderson WR. The relative contribution of leukotriene $B 4$ to the neutrophils chemotactic activity produced by the human alveolar macrophage. J Clin Invest 1987; 80: 1114-1124. 